\title{
ENDOR Spectroscopy and DFT Calculations: Evidence for the Hydrogen-Bond Network Within $\alpha 2$ in the PCET of $E$. coli Ribonucleotide Reductase
}

\author{
Tomislav Argirevic, ${ }^{\dagger}$ Christoph Riplinger, ${ }^{\ddagger}$ JoAnne Stubbe, ${ }^{\S}$ Frank Neese, ${ }^{*}$, and Marina Bennati*,ll, \\ ${ }^{\dagger}$ Max Planck Institute for Biophysical Chemistry, 37077 Göttingen, Germany \\ ${ }^{\ddagger}$ Max Planck Institute for Chemical Energy Conversion, 45470 Mülheim an der Ruhr, Germany \\ ${ }^{\S}$ Department of Chemistry and Biology, Massachusetts Institute of Technology, Cambridge, Massachusetts 02139, United States \\ "Department of Chemistry, University of Göttingen, 37077 Göttingen, Germany
}

\section{Supporting Information}

ABSTRACT: Escherichia coli class I ribonucleotide reductase (RNR) catalyzes the conversion of nucleotides to deoxynucleotides and is composed of two subunits: $\alpha 2$ and $\beta 2 . \beta 2$ contains a stable di-iron tyrosyl radical $\left(\mathrm{Y}_{122}{ }^{\bullet}\right)$ cofactor required to generate a thiyl radical $\left(\mathrm{C}_{439^{\circ}}\right)$ in $\alpha 2$ over a distance of $35 \AA$, which in turn initiates the chemistry of the reduction process. The radical transfer process is proposed to occur by proton-coupled electron transfer (PCET) via a specific pathway: $\mathrm{Y}_{122} \leftrightarrows \mathrm{W}_{48}\left[\right.$ ?] $\leftrightarrows \mathrm{Y}_{356}$ in $\beta 2$, across the subunit interface to $\mathrm{Y}_{731} \leftrightarrows \mathrm{Y}_{730} \leftrightarrows \mathrm{C}_{439}$ in $\alpha 2$. Within $\alpha 2$ a colinear PCET model has been proposed. To obtain evidence

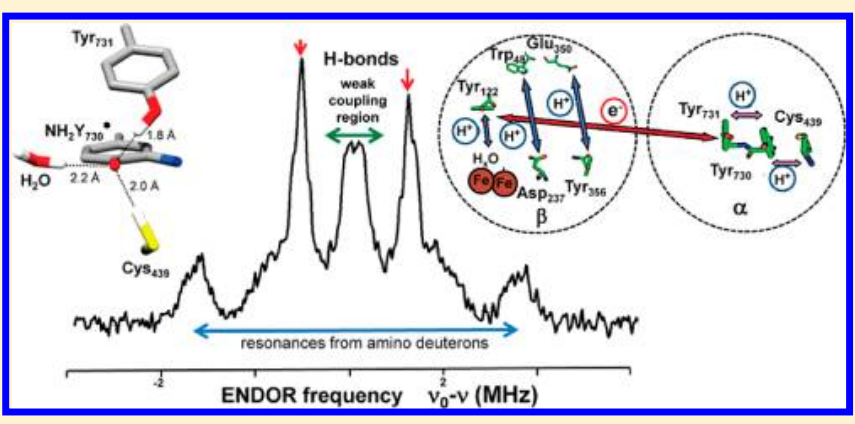
for this model, 3 -amino tyrosine $\left(\mathrm{NH}_{2} \mathrm{Y}\right)$ replaced $\mathrm{Y}_{730}$ in $\alpha 2$, and this mutant was incubated with $\beta 2$, cytidine $5^{\prime}$-diphosphate, and adenosine $5^{\prime}$-triphosphate to generate a $\mathrm{NH}_{2} \mathrm{Y}_{730^{\circ}}$ in $\left.\mathrm{D}_{2} \mathrm{O} .{ }^{2} \mathrm{H}\right]$-Electron-nuclear double resonance (ENDOR) spectra at $94 \mathrm{GHz}$ of this intermediate were obtained, and together with DFT models of $\alpha 2$ and quantum chemical calculations allowed assignment of the prominent ENDOR features to two hydrogen bonds likely associated with $\mathrm{C}_{439}$ and $\mathrm{Y}_{731}$. A third proton was assigned to a water molecule in close proximity $(2.2 \AA \mathrm{O}-\mathrm{H} \cdots \mathrm{O}$ distance $)$ to residue 730 . The calculations also suggest that the unusual $g$-values measured for $\mathrm{NH}_{2} \mathrm{Y}_{730}$ are consistent with the combined effect of the hydrogen bonds to Cys 439 and $\mathrm{Tyr}_{731}$, both nearly perpendicular to the ring plane of $\mathrm{NH}_{2} \mathrm{Y}_{730}$. The results provide the first experimental evidence for the hydrogenbond network between the pathway residues in $\alpha 2$ of the active RNR complex, for which no structural data are available.

\section{INTRODUCTION}

Ribonucleotide reductases (RNRs) convert nucleotides (NDPs) to their corresponding deoxynucleotides (dNDPs) in all organisms based on a catalytic mechanism which involves highly controlled radical chemistry. ${ }^{1,2}$ These enzymes are responsible for generating a balanced pool of the deoxynucleoside triphosphates (dNTPs) and provide the monomeric precursors for DNA replication and repair. ${ }^{3}$ The Escherichia coli class Ia RNR is composed of two homodimeric subunits $\alpha 2$ and $\beta 2$, which form an $\alpha 2 \beta 2$ complex during nucleotide turnover. $\beta 2$ harbors a stable di-iron tyrosyl radical $\left(\mathrm{Y}_{122}{ }^{\bullet}\right)$ cofactor, which is essential for catalysis. Each turnover requires radical propagation from $\mathrm{Y}_{122}$ to the active site in $\alpha 2$, where a cysteinyl radical $\mathrm{C}_{439}{ }^{\bullet}$ is generated and initiates nucleotide reduction. A model for radical propagation has been postulated (Figure 1) based on in silico docking of the $\mathrm{X}$-ray structures of the individual subunits and requires that $\mathrm{Y}_{122}{ }^{\bullet}$ is $\sim 35 \AA$ removed from $\mathrm{C}_{439} \cdot{ }^{\bullet} \cdot{ }^{4,5}$ Using pulsed electron double resonance (PELDOR) spectroscopy, our distance measurements between $\mathrm{Y}_{122}{ }^{\bullet}$ and a nitrogen radical from the mechanism-based inhibitor $2^{\prime}$-azido- $2^{\prime}$-deoxyuridine 5 -diphosphate trapped in the active site of $\alpha 2$ provided the first evidence for the long distance between the two sites. ${ }^{6}$

The unprecedented mechanism for radical initiation over a pathway of conserved redox active amino acids, $\mathrm{Y}_{122} \bullet \leftrightarrows\left[\mathrm{W}_{48}\right.$ ?] $\leftrightarrows \mathrm{Y}_{356}$ on $\beta 2$ and $\mathrm{Y}_{731} \leftrightarrows \mathrm{Y}_{730} \leftrightarrows \mathrm{C}_{439}$ in $\alpha 2$, has attracted considerable attention in the past decade. Mutagenesis studies provided the first experimental support for the importance of the proposed pathway residues. ${ }^{7,8}$ However, recent studies using site-specifically incorporated unnatural tyrosine analogs with altered redox potentials and $\mathrm{p} K_{\mathrm{a}} \mathrm{s}$ in place of pathway residues $^{9-11}$ and studies with photoinitiated RNRs ${ }^{12}$ have suggested a more detailed chemical mechanism for this longrange oxidation. Specifically colinear and orthogonal proton coupling to the electron transfer (PCET) steps within $\alpha 2$ and $\beta 2$, respectively, have been proposed. ${ }^{13,16}$ The mechanism of oxidation across the subunit interface remains unclear, as the Cterminal 35 amino acids of $E$. coli $\beta 2$, which include pathway residue $\mathrm{Y}_{356}$, are not visible in the structure.

Received: July 22, 2012

Published: October 16, 2012 


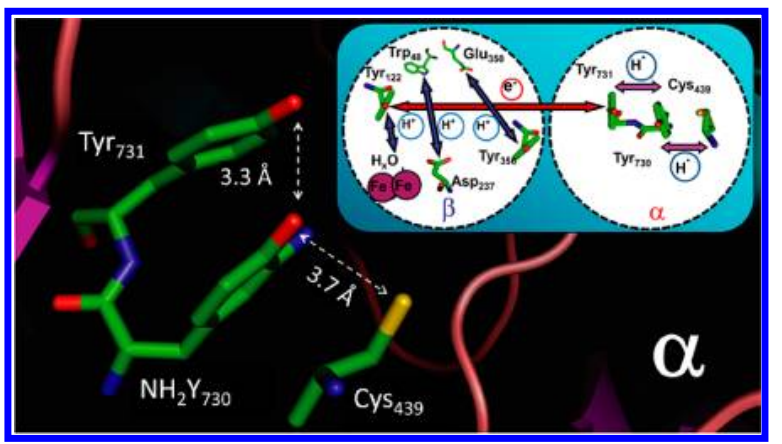

Figure 1. Crystal structure of the $\mathrm{Y}_{730} \mathrm{NH}_{2} \mathrm{Y}-\alpha 2$ mutant of $E$. coli $\mathrm{RNR}$ from ${ }^{19}$ (molecule A) showing the residues $\mathrm{Y}_{731}, \mathrm{NH}_{2} \mathrm{Y}_{730}$, and $\mathrm{C}_{439}$ in the PCET pathway. The $\mathrm{O}-\mathrm{O}$ and $\mathrm{O}-\mathrm{S}$ distances between the essential amino acid residues are marked. The inset shows the current model for the long-range $(\sim 35 \AA)$, reversible PCET starting at $\mathrm{Y}_{122}$ in $\beta 2$ and reaching $C_{439}$ in $\alpha 2$. Note that the position of $Y_{356}$ is unknown as the $\mathrm{C}$-terminus is disordered in all $\mathrm{X}$-ray structures of $\beta 2$.

The original crystallographic data of $\alpha 2$, indicated that the orientation of $Y_{731}$ and $Y_{730}$ relative to each other (Figure 1, inset) is unusual and suggested a colinear PCET mechanism. ${ }^{14-17}$ The importance of Y731 and Y730 in the initiation process is supported by a number of different types of experiments. Mutagenesis studies in which $Y_{731}$ and $Y_{730}$ were replaced by $\mathrm{F}$ were inactive, and the structures of the mutant $\alpha 2$ s were not perturbed, demonstrating their importance. ${ }^{8}$ The first direct support for the redox role of $\mathrm{Y}_{356}, \mathrm{Y}_{730}$, and $\mathrm{Y}_{731}$ was obtained by site-specific incorporation of a variety of tyrosine analogues using either expressed protein ligation ${ }^{18}$ or the suppressor tRNA/aminoacyl-tRNA synthetase (RS) methodology. ${ }^{11}$ The insertion of 3-aminotyrosine $\left(\mathrm{NH}_{2} \mathrm{Y}\right)$ in place of each of these $\mathrm{Ys}$, for example, revealed that the $\mathrm{Y}_{122}{ }^{\bullet}$ can oxidize $\mathrm{NH}_{2} \mathrm{Y}$ to an amino tyrosyl radical $\left(\mathrm{NH}_{2} \mathrm{Y}^{\bullet}\right)$ in the presence of the appropriate substrate and allosteric effector pair while retaining low levels of enzymatic activity. ${ }^{11,19,20}$ Thus, the $\mathrm{NH}_{2} \mathrm{Y}^{\bullet}$ s, produced in a kinetically competent fashion, represent excellent mechanistic probes of a pathway radical intermediate involved in nucleotide reduction.

The radical generated in $\mathrm{NH}_{2} \mathrm{Y}_{730}-\alpha 2$ E. coli $\mathrm{RNR}$ was recently characterized by multifrequency EPR spectroscopy ${ }^{21}$ and revealed unprecedented $g$-values $\left(g_{x}=2.0052, g_{y}=2.0042\right.$, and $\left.g_{z}=2.0022\right)$, suggesting that it resides in an environment with unusual electrostatic and hydrogen-bond (H-bond) interactions. $^{22}$ This study prompted us to examine in more detail the structure around $\mathrm{NH}_{2} \mathrm{Y}_{730}$ to find evidence for the proposed intermolecular $\mathrm{H}$-bonding network to the next essential pathway residues, $\mathrm{Y}_{731}$ and $\mathrm{C}_{439}$. For this purpose we have performed electron-nuclear double resonance spectroscopy (ENDOR) at high fields and frequencies (3.4 T/94 $\mathrm{GHz}$ ) to detect the hyperfine coupling to protons that were exchanged to deuterons using $\mathrm{D}_{2} \mathrm{O}$ buffer. Specifically, the method at high fields permits separation of the resonances of the deuterons from the ${ }^{1} \mathrm{H}$ resonances of nonexchangeable protons or of other low-gamma $(\gamma)$ nuclei such as ${ }^{14} \mathrm{~N}$. Furthermore, the high-field/high-frequency approach allows orientation-selective experiments to be carried out. ${ }^{23}$ Here, only a few molecular orientations are excited within individual experiments permitting the reconstruction not only of the magnetic hyperfine tensors but also of their orientations in the molecular frame. Nevertheless, the interpretation of the EPR data in terms of a structure requires the use of sophisticated quantum chemical calculations, as was shown in previous work. ${ }^{24-27}$ DFT calculations can generate possible molecular structures of the trapped intermediate that serve as a model(s) for the simulation of the EPR data. The calculated EPR parameters can then be employed for the interpretation of the spin-Hamiltonian parameters of the intermediate. In the present study we demonstrate that the combination of the ENDOR and DFT methods has allowed the assignment of exchangeable protons with their distances and orientations around the $\mathrm{NH}_{2} \mathrm{Y}_{730}{ }^{\circ}$ intermediate. Moreover, our study detects an exchangeable proton that given the $\mathrm{X}$-ray structures and the observed magnetic parameters is very likely a conserved water molecule at close distance $(2.2 \AA \mathrm{O}-\mathrm{H} \cdots \mathrm{O}$ distance) from the oxygen of $\mathrm{NH}_{2} \mathrm{Y}_{730^{\circ}}$. This water molecule was previously mentioned by Siegbahn and co-workers but was not used in their model ${ }^{14}$ and has not been considered to date in a possible PCET mechanism within $\alpha 2$. The present work has used combined experimental and theoretical approaches to establish the H-bond network in the PCET pathway in $\alpha 2$ of an active RNR complex for which no X-ray structure is available. The results are used to rationalize the radical transfer between $\mathrm{Y}_{731}$ $\leftrightarrows \mathrm{Y}_{730} \leftrightarrows \mathrm{C}_{439}$ in $\alpha 2$

\section{RESULTS}

$94 \mathrm{GHz}$ ENDOR Spectra of Exchangeable Protons Coupled to $\mathrm{NH}_{2} \mathrm{Y}_{730^{\circ}}$. ENDOR spectra of a radical reveal the hyperfine couplings to magnetic nuclei that are in the vicinity (usually approximately $\leq 5 \AA$ ) of this center. When the buffer is exchanged with $\mathrm{D}_{2} \mathrm{O}$, a deuterium ENDOR spectrum displays the resonances of exchangeable protons, such as those attached to heteroatoms including water molecules and amide protons in proximity. Each deuteron contributes to the spectrum a line pattern characterized by a hyperfine and quadrupole splitting (quartet). A representative deuterium ENDOR spectrum of the $\mathrm{NH}_{2} \mathrm{Y}_{730^{\circ}}$ radical trapped during reaction of $\mathrm{NH}_{2} \mathrm{Y}_{730^{-}} \alpha 2, \beta 2$, cytidine $5^{\prime}$-diphosphate/adenosine 5 -triphosphate (CDP/ ATP) in $\mathrm{D}_{2} \mathrm{O}$ buffer is displayed in Figure 2. The spectrum shows a complex deuterium ENDOR signal with a spectral width $( \pm \sim 2 \mathrm{MHz})$ consistent with the strong deuterium resonances of the $\mathrm{ND}_{2}$-group of the $\mathrm{NH}_{2} \mathrm{Y}^{\circ}$ probe, as previously reported from the analysis of the EPR spectra, ${ }^{21}$ and other overlapping signals. Nevertheless, the most prominent features are two strong peaks at around \pm 0.6 $\mathrm{MHz}$ and a Pake pattern of at least one weakly coupled deuteron around the deuterium Larmor frequency. The strong peaks at $\pm 0.6 \mathrm{MHz}$ lie in a region expected for coupled $\mathrm{H}$ bonds. $^{28,29}$ To gain insight into the possible number of exchangeable protons that could contribute to the ENDOR spectrum, the crystal structure of the $\mathrm{NH}_{2} \mathrm{Y}_{730^{-}} \alpha 2$ mutant in the resting state was examined. However, it should be kept in mind that the X-ray structure of the active $\alpha 2 \beta 2 \mathrm{RNR}$ complex is unknown. The predominant structure reported of $\mathrm{NH}_{2} \mathrm{Y}-\alpha 2^{19}$ (Figure 1) is very similar to the wild-type (wt) structure (see also overlaid structures in Figure S8) and suggests that several exchangeable protons might be found in a distance range of $\leq 5$ $\AA$ (Figure 2, inset) in the active complex. First, the oxygen of $\mathrm{Y}_{731}$, the sulfur of $\mathrm{C}_{439}$ and the oxygen of $\mathrm{Y}_{413}$ are all protonated and could contribute $\mathrm{H}$-bonding interactions with $\mathrm{NH}_{2} \mathrm{Y}_{730}$. Second, two water molecules reside at distances $<\sim 5 \AA$, but only one is conserved in the structure of resting wt $\alpha 2$.

Couplings to External $\mathrm{H}$-bonds. To increase the resolution of the ENDOR experiment we recorded ENDOR spectra of the segments in the region of $\pm 1.5 \mathrm{MHz}$ together with their orientation selection (Figure $3 b$ ). The unusual 


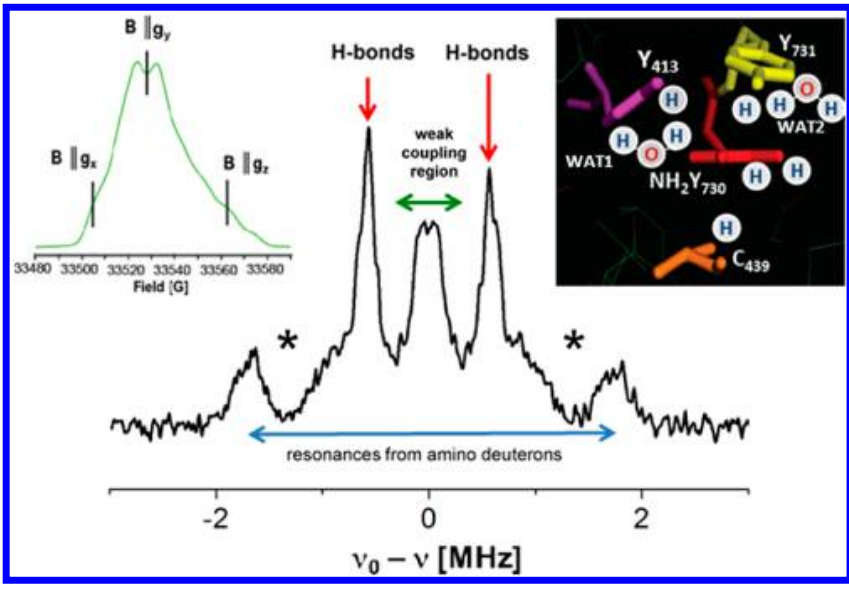

Figure 2. 94-GHz ${ }^{2} \mathrm{H}-\mathrm{Mims}$ ENDOR spectrum of $\mathrm{NH}_{2} \mathrm{Y}_{730}{ }^{\circ}$ in $\mathrm{D}_{2} \mathrm{O}$ assay buffer recorded after reaction of $\mathrm{NH}_{2} \mathrm{Y}_{730}$ with CDP/ATP and quenching after $30 \mathrm{~s}$. The spectrum was recorded at B $\| g_{y}$ (see EPR spectrum on the inset left). Different resonant regions are indicated with arrows and discussed in the text. The stars denote blind spots given by the Mims ENDOR sequence. The inset reveals the resting structure of $\mathrm{NH}_{2} \mathrm{Y}_{730}-\alpha 2$ from ref 19 and possible protons around this residue. The water molecules have been denoted WAT1 and WAT2, as described in the text. Exptl. conditions (for field sweep): $T=70 \mathrm{~K}$, MW $(\pi / 2)=32 \mathrm{~ns}, \tau=260 \mathrm{~ns}, \mathrm{MW}(\pi)=64 \mathrm{~ns}$, repetition time $=3$ $\mathrm{ms}$, shots $/$ point $=50$, scans $=700$. Conditions (for ENDOR): $T=10$ $\mathrm{K}$, MW pulse $(\pi / 2)=20 \mathrm{~ns}, \tau=360 \mathrm{~ns}$, RF pulse $=40 \mu \mathrm{s}$, repetition time $=150 \mathrm{~ms}, 1700$ scans.

intensity of the peaks occurring at $\pm 0.6 \mathrm{MHz}$ suggested that they could constitute the perpendicular component of an axially symmetric hyperfine tensor $\left(\mathbf{A}_{\perp}\right)$ arising from more than one deuteron. If this tensor was purely dipolar, the wings at about 1-1.2 $\mathrm{MHz}$ could represent the $\mathbf{A}_{\|}$component, however the amino deuterons also contribute in this region and are not distinguishable. We note that the precise form of the $\mathrm{ND}_{2}$ tensors is still to be established, as previous EPR simulations ${ }^{21}$ were not sensitive to small tensor components (i.e., $\leq 6 \mathrm{MHz}$ for ${ }^{1} \mathrm{H}$ or about $\leq 1 \mathrm{MHz}$ for ${ }^{2} \mathrm{H}$ ).

The orientation selective spectra in Figure $3 \mathrm{~b}$ displayed a pronounced attenuation of the $\pm 0.6 \mathrm{MHz}$ peaks at $\mathrm{B} \| g_{z}$. Attempts to simulate the spectra using either one or two deuterons with a pure dipolar tensor of $2 \mathrm{~A}_{\perp}=-\mathbf{A}_{\|} \approx 1.2 \mathrm{MHz}$ and $g_{z} \| \mathbf{A}_{\|}$did not reproduce the observed intensities, when the absorption of the amino deuterons was taken into account as previously reported. ${ }^{21} \mathrm{We}$ also note that part of the tensor belonging to the $\pm 0.6 \mathrm{MHz}$ resonances might be hidden in the central part of the ENDOR spectrum, where the intensities are attenuated by the central hole of the Mims sequence ${ }^{30}$ and overlap with the weakly coupled deuteron(s). Therefore, the results indicated that the complete form of the hyperfine tensors cannot be easily disentangled from the observed ENDOR spectra.

The orientation selected ENDOR spectra in Figure 3c display the region of $\pm 0.4 \mathrm{MHz}$ with higher resolution. In this region, the ENDOR line shape is reminiscent of a dipolar powder pattern from mainly one deuteron, with the orientation selectivity leading to sharpness of the spectra at B $\|_{g_{x}}$ and $g_{z}$. The position of the outer edges shifts only slightly between $0.25\left(g_{x}\right)$ and $0.3 \mathrm{MHz}\left(g_{z}\right)$, suggesting a counteracting effect of orientation-dependent hyperfine and quadrupole splittings. As in the high-field limit the quadrupole coupling splits the ENDOR line symmetrically around the hyperfine value, the

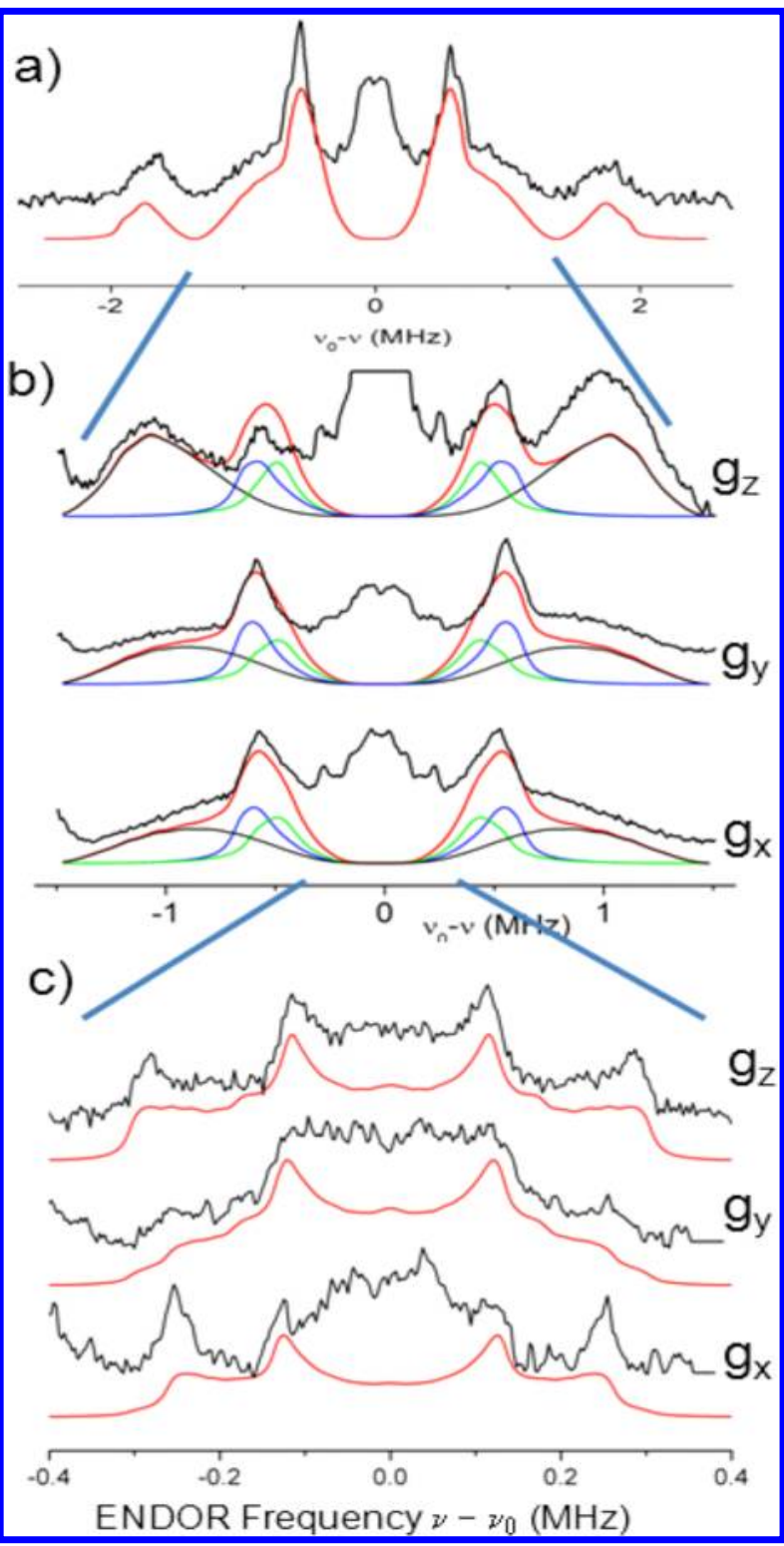

Figure 3. (a) ${ }^{2} \mathrm{H}$-Mims ENDOR spectrum of $\mathrm{NH}_{2} \mathrm{Y}_{730} \bullet$ in $\mathrm{D}_{2} \mathrm{O}$ assay buffer of the weakly coupled regions (black, from Figure 2) and simulation (red). (b,c) Orientation selected ENDOR spectra recorded across the EPR line (Figure 2, inset). The blue lines connect the spectra segments from (a) to (c), which have been expanded. (b) Conditions: $T=10 \mathrm{~K}$, MW pulse $(\pi / 2)=20 \mathrm{~ns}, \tau=320 \mathrm{~ns}$, RF pulse $=40 \mu \mathrm{s}$, repetition time $=150 \mathrm{~ms}, 2000-3000$ scans $/$ spectrum, 1 shot/point, random RF acquisition. The simulation (red) has been decomposed in the three separate simulations with the parameters for $\mathrm{Y}_{731}{ }^{2} \mathrm{HO}$ (blue spectra) and $\mathrm{C}_{439}{ }^{2} \mathrm{HO}$ (green spectra) and the amino deuterons $\left({ }^{2} \mathrm{H}\right)_{2} \mathrm{~N}$ (black) as listed in Table 1. (c) Exptl. conditions as in (b) but $\tau=360$ ns. Simulation parameters are reported in Table 1 . Average rmsd were about 0.09 for (b) and 0.07 for (c), as explained in Methods section.

observed line shape sets boundaries for the hyperfine tensor of this weakly coupled deuteron with $\mathbf{A}_{\|} \approx 0.4 \mathrm{MHz}$. On the other hand, a further determination of the tensor elements and particularly their orientations is aggravated by the uncertainty about the number of weakly coupled deuterons contributing to this region.

Overall, the ENDOR spectra of Figure 3 contain the fingerprints of the $\mathrm{H}$-bond network around $\mathrm{NH}_{2} \mathrm{Y}_{730^{\circ}}$, however 


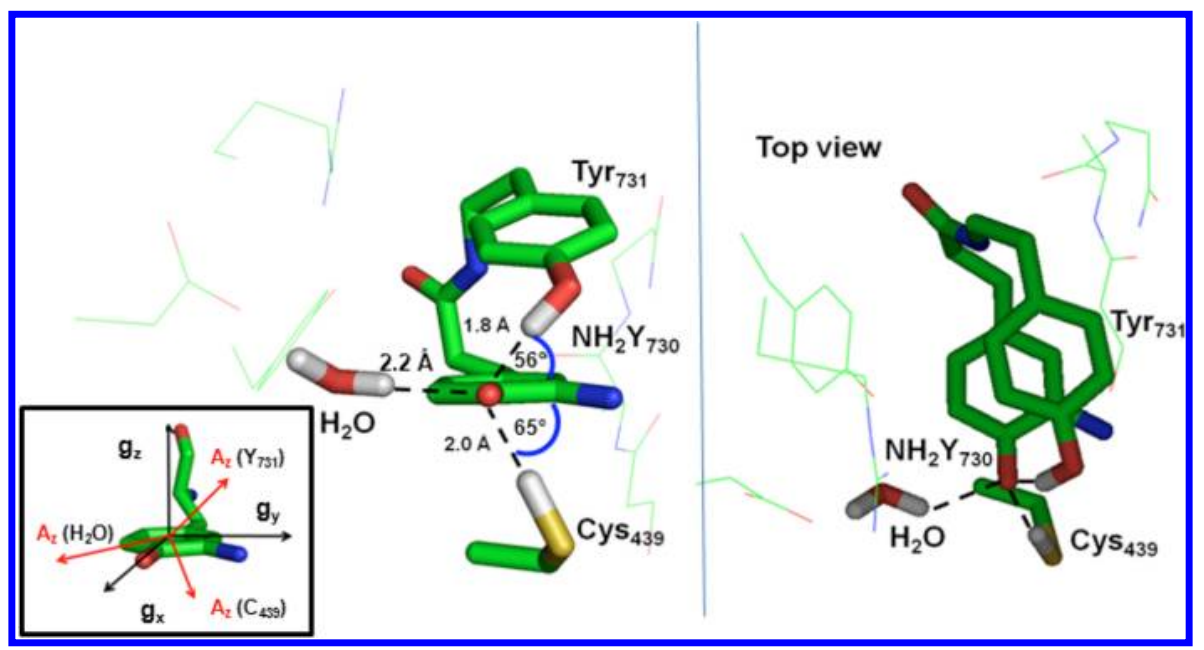

Figure 4. Combined EPR and DFT model for the H-bond network around $\mathrm{NH}_{2} \mathrm{Y}_{730^{\circ}}$ in $\alpha 2$. Left and right are side and top views, respectively, of distances and out-of-plane angles of the H-bonds and to WAT1 within the optimized DFT model 4. Inset: Location of the $g$ tensor within the $\mathrm{NH}_{2} \mathrm{Y}^{\bullet}$ structure. The direction of the hyperfine tensor component $\mathbf{A}_{z}$ of the three hydrogen/deuteron couplings is also schematically drawn.

spectral simulations could not be performed a priori due to the large and unknown number of possible couplings. We note that the ENDOR simulation requires at least eight independent parameters for each deuteron, i.e., three hyperfine and two quadrupole tensor components, three Euler angles relating A and $g$ tensors if $\mathbf{A}$ and $\mathbf{Q}$ are assumed to be collinear. Not much rationale can be applied for the choice of these parameters, if a structural model and subsequent prediction of the related EPR parameters are lacking. Such a model can be obtained from DFT calculations, if possible energy-minimized structures of the radical intermediate within its protein environment are examined.

Optimized Structure of $\mathrm{NH}_{2} \mathrm{Y}_{730^{\circ}}$ from Combined DFT and ENDOR Results. In order to find an optimized structure with magnetic parameters compatible to the ENDOR spectra, six different models were investigated by DFT. All structures used the coordinates of $\alpha-\mathrm{NH}_{2} \mathrm{Y}_{730}$ as input but differed in the number and arrangement of the water molecules. Because in the $\mathrm{X}$-ray structure of $\mathrm{NH}_{2} \mathrm{Y}_{730^{-}} \alpha_{2}$, the amino tyrosine is reduced, and the enzyme is not active; energy-minimized structures were evaluated on the basis of their computed EPR parameters for $\mathrm{NH}_{2} \mathrm{Y}_{730}{ }^{\circ}$ as compared with the previously reported EPR parameters, ${ }^{21}$ i.e., the $g$-values and the large hyperfine couplings to the $\beta$-methylene hydrogens and the ${ }^{14} \mathrm{~N}$ nucleus of the amino group.

Specifically, two structures contained only the water molecule (WAT1) located between $\mathrm{NH}_{2} \mathrm{Y}_{730}$ and $\mathrm{Y}_{413}$ (Figure 2 , inset), which is conserved in most $\mathrm{X}$-ray structures, $5,19,31,32$ whereas three other structures took into account a second water molecule visible in $\alpha-\mathrm{NH}_{2} \mathrm{Y}_{730}$ and located at $\sim 5 \AA$ from both the nitrogen and the oxygen atom of $\mathrm{NH}_{2} \mathrm{Y}^{\bullet}$ (Figure 2, inset). We note that the second water molecule is not conserved in the wt structure but could be present in the $\mathrm{NH}_{2} \mathrm{Y}$ mutant and contribute to the ENDOR spectra. The optimized cluster models are illustrated in Figures S1-S5 and in Figure 4. However, the three structures (in SI models 1-3) with two water molecules were discarded and not analyzed further because they show that the second water molecule would interact strongly either with the carbonyl group of residue $\mathrm{S}_{694}$ (Figure $\mathrm{S} 1$ ) or with the amino group of $\mathrm{NH}_{2} \mathrm{Y}^{\bullet}$ (Figures S2 and S3). Both situations would give rise to nitrogen and $\mathrm{C}_{\beta}$ methylene proton tensors for $\mathrm{NH}_{2} \mathrm{Y}^{\bullet}$ that are not compatible with our EPR data. ${ }^{21}$ Structure 5 (see Figure S4) with only one water shows this water molecule with one hydrogen at a $1.9 \AA$ from the oxygen of $\mathrm{NH}_{2} \mathrm{Y}^{\bullet}$. The calculated dipolar tensor for this deuteron has eigenvalues that by far exceed the experimentally observed values in Figure 3C. Finally, structure 4 (Figure 4) shows the water molecule with a proton at a distance of $2.2 \AA$. This arrangement generates a dipolar coupling tensor for this proton that is quite close to the experimental results (Table 1). Also, the DFT calculation of structure 4 predicts that both $\mathrm{H}$-bonds to the next essential pathway residues, $\mathrm{Y}_{731}$ and $\mathrm{C}_{439}$, should be observable in the ENDOR experiments. The calculated couplings are reported in Table 1. The H-bond lengths to $\mathrm{Y}_{731}$ and $\mathrm{C}_{439}$ are quite different from one another (1.8 and 2.0 ̊ respectively, Figure 4). The form of the hyperfine tensor strongly depends on the out-of-plane angle between the bond vector and the $\mathrm{NH}_{2} \mathrm{Y}^{\bullet}$ ring, as indicated from systematic calculations that explore this dependency (data not shown; this behavior has previously been described for a similar system, a quinone radical anion). ${ }^{33}$ This dependency is readily rationalized when considering that the $\mathrm{H}$ bond starts to overlap with the $\pi$-orbitals of the $\mathrm{NH}_{2} \mathrm{Y}^{\bullet}$ for large out-of-plane angles, as was already reported. ${ }^{33}$ Thus, the form of the hyperfine tensor can significantly deviate from a typical axially symmetric dipolar tensor that we observed for the $\mathrm{H}$ bond to the essential tyrosyl radical diiron-cofactor in Saccharomyces cerevisiae RNR. ${ }^{29}$ Also, for large out-of-plane angles, the point-dipole model cannot be used to derive the $\mathrm{H}$ bond length from the hyperfine couplings.

The calculated EPR parameters derived from model 4 for five deuterons, i.e., $\mathrm{Tyr}_{731}$-OD, $\mathrm{Cys}_{439^{-}} \mathrm{OD}$, WAT1-OD, and the amino deuterons, were used as input for the simulations of the ENDOR spectra. Specifically, all Euler angles predicted by the DFT calculation for the couplings to $\mathrm{Tyr}_{731}$-OD and $\mathrm{Cys} \mathrm{s}_{439}$-OD were kept fixed, and the hyperfine and quadrupole tensors were allowed to change as much as $\pm 20-30 \%$ in order to reproduce the position and the relative intensities of the ENDOR lines. The values obtained in this way should represent boundaries for the magnitude of the hyperfine tensors. The obtained simulations are presented in Figure 3, and the simulation parameters are compared with the DFT values in Table 1. As a result, only minor refinement of the DFT values was required to obtain reasonable agreement between simulations and 
Table 1. Summary of Magnetic and Structural Parameters of the Exchangeable Deuterons Coupled to $\mathrm{NH}_{2} \mathrm{Y}^{\bullet}$ from Combined HF-ENDOR and DFT Calculations ${ }^{a}$

\begin{tabular}{|c|c|c|c|c|c|c|c|c|c|c|}
\hline & $\mathbf{A}_{x}$ & $\mathbf{A}_{y}$ & $\mathbf{A}_{z}$ & $\alpha$ & $\beta$ & $\gamma$ & $Q_{1}$ & $\mathbf{Q}_{2}$ & $\mathbf{Q}_{3}$ & $r_{\mathrm{O}-\mathrm{D}}$ \\
\hline $\begin{array}{l}\mathrm{Cys}_{439}-\mathrm{SD} \\
\operatorname{sim}\end{array}$ & -1.1 & -0.95 & 0.6 & -17 & 38 & -44 & -0.03 & -0.02 & 0.06 & \\
\hline DFT & -1.0 & -0.8 & 0.6 & -17 & 38 & -44 & -0.04 & -0.03 & 0.07 & 2.0 \\
\hline $\begin{array}{l}\mathrm{Tyr}_{731}-\mathrm{OD} \\
\operatorname{sim}\end{array}$ & -1.25 & -1.15 & 0.7 & -166 & 47 & 102 & -0.02 & -0.03 & 0.06 & \\
\hline $\begin{array}{l}\text { DFT } \\
{ }^{2} \mathrm{H}_{2} \mathrm{O}\end{array}$ & -1.70 & -1.15 & 0.73 & -166 & 47 & 102 & -0.04 & -0.06 & 0.11 & 1.8 \\
\hline $\operatorname{sim} H(1)$ & -0.21 & -0.21 & 0.42 & 6 & -81 & 10 & 0.14 & -0.06 & -0.05 & \\
\hline $\begin{array}{l}\text { DFT H(1) } \\
{ }^{2} \mathrm{H}_{2} \mathrm{~N}\end{array}$ & -0.31 & -0.28 & 0.64 & 6 & -81 & 55 & 0.14 & -0.06 & -0.07 & 2.2 \\
\hline $\operatorname{sim} H(1)$ & -3.3 & 0 & -2.7 & 7 & 6 & 75 & -0.04 & 0.11 & -0.06 & \\
\hline DFT H(1) & -3.3 & -0.1 & -2.7 & 7 & 6 & 75 & -0.05 & 0.13 & -0.07 & \\
\hline $\operatorname{sim} H(2)$ & -3.8 & 0 & -2.9 & 0 & -5 & -30 & 0.14 & -0.08 & -0.06 & \\
\hline DFT H(2) & -4.0 & 0.1 & -2.6 & 4 & 5 & -30 & 0.14 & -0.08 & -0.06 & \\
\hline
\end{tabular}

${ }^{a}$ All hyperfine and quadrupole values are given in MHz. The signs of the couplings from the simulation are only relative to each other within one tensor. The Euler angles $(\alpha, \beta, \gamma)$ in degrees are defined from the $\mathbf{A}$ to the $g$ tensor with the second rotation around the $y$ axis, counterclockwise. The orientation of the $g$ tensor as well as the orientation of the $\mathbf{A}_{z}$ direction for the three weakly coupled deuterons is illustrated in Figure 4 . The latter is defined such that it coincides with the bond direction. Instead, for the amino deuterons, the $\mathrm{N}-\mathrm{H}$ bond defines the $y$ direction. Distances are given in $\AA$. Uncertainties in the experiment and calculations are estimated up to $20 \%$. The spin density distribution, as derived from the Loewdin

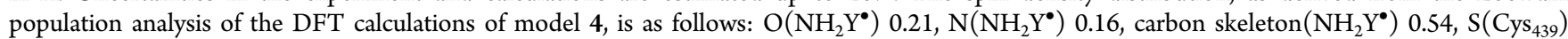
$0.01, \mathrm{O}\left(\mathrm{Tyr}_{731}\right) 0.01$.

experimental spectra, with rmsd $<0.1$ (for spectra normalized to unity). The simulation of the strong peaks at $\pm 0.6 \mathrm{MHz}$ is reproduced by the $\mathbf{A}_{x} \approx \mathbf{A}_{y}$ components of almost axially symmetric tensors, as predicted for the $\mathrm{H}$-bonds to $\mathrm{Tyr}_{731}$ and Cys $_{439}$. However, in contrast to typical dipolar tensors, here we find $\left|\mathbf{A}_{x, y}\right|>\left|\mathbf{A}_{z}\right|$ due to a nonzero isotropic coupling. Notably, the two tensors cannot be distinguished in the experimental spectra, but the intensity of both deuterons is required to reproduce the overall line shape, as also illustrated by the simulation of the single components in Figure $3 \mathrm{~b}$. The form of the tensors for these $\mathrm{H}$-bonds is consistent with the observed attenuation of the strong peaks $\left(\mathbf{A}_{x, y}\right)$ at B $\| g_{z}$, as $g_{z}$ is close to $\mathbf{A}_{z}$, with the latter pointing to $\mathrm{Tyr}_{731}$ and/or $\mathrm{Cys}_{439}$ located above and/or below the $\mathrm{NH}_{2} \mathrm{Y}_{730}$ ring (Figure 4). The resonance of the $\mathbf{A}_{z}$ component(s) remains invisible in the spectrum due to the overlap with the matrix peak. This region is also not reproduced by the simulation because of the hole caused by the Mims ENDOR preparation function.

The simulation of the weakly coupled deuteron required an overall scaling of the DFT hyperfine tensor of about $30 \%$, which is likely caused by a minor deviation of the DFT predicted distance with respect to the experimental distance. On the other hand, the orientation dependence of the spectra (Figure 3c) was consistent with the calculated direction of the $\mathbf{A}$ and $\mathbf{Q}$ tensors for the closest deuteron of WAT1. Indeed $\mathbf{A}_{z}$ for this interaction lies almost in the tyrosine plane and points between $\mathrm{g}_{x}$ and $-\mathrm{g}_{y}$ (Figure 4). Thus, the results strongly support the assignment of this deuteron to WAT1. We observe that the simulation requires $\mathbf{A}_{z}$ closer to $g_{x}$ than predicted by the DFT (Euler angle $\gamma$ ). Again, the deviation might suggests a small displacement of the water but could also be within the combined experimental and computational uncertainty.

The simulation of the weakly coupled deuteron in Figure $3 \mathrm{c}$ does not entirely reproduce the matrix peak, which indicates that some other deuterons (presumably the second deuteron of WAT1) contribute to the matrix peak. Finally, the $\mathbf{A}_{y}$ tensor components of the $\mathrm{ND}_{2}$ resonances are also predicted around zero frequencies but not distinguishable. These resonances likely contribute the offset observed under the deuteron spectrum of WAT1. Moreover, the tensors of $\mathrm{ND}_{2}$ extend over the entire ENDOR spectrum, with the remaining principal axis values $\mathbf{A}_{x}$ and $\mathbf{A}_{z}$ predicted far outside the resonances of the H-bonds. This further supports our assignment of the strong peaks at $\pm 0.6 \mathrm{MHz}$ to the external H-bonds.

DFT Calculations of the $\boldsymbol{g}$-Tensor Support Strong $\mathrm{H}$ Bond Interactions to $\mathrm{NH}_{2} \mathrm{Y}_{730^{\circ}}$. We used the optimized structure (model 4) and further DFT calculations to rationalize the $g$-tensor observed for $\mathrm{NH}_{2} \mathrm{Y}_{730^{\circ}}$, which is the EPR parameter that is most sensitive to the electrostatic environment of a radical. Table 2 displays the $g$-tensors calculated for a set of model systems (see Table 2, entries 2-9) compared to the experimental value for the RNR mutant (see Table 2, entry 1).

In the largest and most realistic model systems investigated here, eight amino acid residues surrounding $\mathrm{NH}_{2} \mathrm{Y}_{730}{ }^{\circ}$ are included (Figure S6a). The initial coordinates were taken from the predominant structure of $\alpha-\mathrm{NH}_{2} \mathrm{Y}_{730}$ (see Figure 1) ${ }^{19}$ and subjected to constrained geometry optimization. The water molecule (WAT1) between $\mathrm{Y}_{413}$ and $\mathrm{NH}_{2} \mathrm{Y}_{730}$ is present in model 4 (entry 2) but was omitted in model 6 (entry 3; see also Figure S5 for comparison). For both models 4 and 6 a $g_{x}$ value is obtained that is very close to our experimental results (within the inherent accuracy of the theoretical methodology, i.e., $\pm 0.5 \mathrm{ppt}$ ). This shows on one hand that the model size is sufficiently large, but on the other hand that the $g$-tensor alone cannot be used to decide on the existence of the water molecule in the experimental structure. When comparing the experimental $g_{x}$-value to the calculated $g_{x}$-value of the isolated radical (entry 8) a substantial difference is observed $\left(\Delta \mathrm{g}_{x}=0.9 \mathrm{ppt}\right)$. This is likely indicative for strong $\mathrm{H}$-bond interactions from the protein environment. In order to rationalize the effect of the intermolecular H-bonds in the protein on the $g_{x}$-value, the large models were systematically reduced in size (starting from entry 2 ) and the effect on the $g$-values calculated. Entry 4 shows the 
Table 2. Comparison of Computed $g$-Values from DFT Models with Experiment ${ }^{a}$

\begin{tabular}{|c|c|c|c|c|}
\hline & & $g_{x}$ & $g_{y}$ & $g_{z}$ \\
\hline 1 & Experiment & 2.0052 & 2.0042 & 2.0022 \\
\hline & DFT model & \multicolumn{3}{|c|}{ Deviation from experiment [in ppt] } \\
\hline 2 & Model 4 (with WAT1) & -0.3 & -0.1 & -0.4 \\
\hline 3 & Model 6 (without WAT1) & -0.1 & -0.1 & -0.3 \\
\hline 4 & $\mathrm{NH}_{2} \mathrm{Y}_{730^{\circ}}-\mathrm{Tyr}_{731}-\mathrm{C}_{439}-$ WAT1 & $-0,6$ & $-0,3$ & -0.5 \\
\hline 5 & $\mathrm{NH}_{2} \mathrm{Y}_{730^{\circ}-\mathrm{Tyr}_{731}-\mathrm{C}_{439}}$ & -0.2 & $-0,2$ & -0.4 \\
\hline 6 & $\mathrm{NH}_{2}$ & 0.3 & 0.2 & -0.2 \\
\hline 7 & $\begin{array}{c}1.99 \\
\mathrm{NH}_{2} \mathrm{Y}_{730^{\circ}}-\mathrm{Cys}_{439}\end{array}$ & 0.8 & 0.1 & -0.4 \\
\hline 8 & 2-amino-4-methyl-phenol radical (2-AMPR) & 0.9 & 0.3 & 0.0 \\
\hline 9 & 2-amino-dimethyl-4-methyl-phenol radical & 1.7 & 0,4 & 0.0 \\
\hline
\end{tabular}

${ }^{a_{T}}$ The optimized structure without water (entry 3, model 6) is shown in Figure S5. The optimized structure with water (entry 2, model 4) is shown in Figure 4. Small model systems were obtained by omitting residues of model 4, which are not involved in the PCET pathway. H-bond lengths are given in Å. Geometries and EPR parameters are calculated using COSMO $(\varepsilon=4.0)$. The uncertainty in the experimental values (entry 1$)$ at 180 $\mathrm{GHz}$ is $\pm 0.1 \mathrm{ppt}$. The unit ppt refers as part per thousand of the $g$-value.

results for a model containing only the PCET pathway residues and WAT1, i.e., without the second sphere residues present in entries 2 and 3 . With this model the $g_{x}$-value is decreased compared to entry 2 . This is due to the missing effect of the surrounding residues on the strength of the $\mathrm{H}$-bond between WAT1 and $\mathrm{NH}_{2} \mathrm{Y}_{730}$ (for more information see SI and Figure S7). Removing WAT1 (entry 5) increases the $g_{x}$-value and brings it again back into the range of the experimental results. Removing the H-bonding partners $\mathrm{Cys}_{439}$ (entry 6) or $\mathrm{Tyr}_{731}$ (entry 7) increases the $g_{x}$-value further by 0.5 and $1.0 \mathrm{ppt}$, respectively. Comparing entries 3 and 8 shows that it is mostly the combined effect of the H-bonds to $\mathrm{Cys}_{439}$ and $\mathrm{Tyr}_{731}$, both nearly perpendicular to the ring plane of $\mathrm{NH}_{2} \mathrm{Y}_{730^{\circ}}$, which substantially shifts the predicted $g_{x}$-value toward the experimental value. The H-bond to WAT1 also has an effect on the $g_{x}$-value, but it is strongly influenced by the second sphere residues.

The isolated radical (entry 8) contains an additional intramolecular H-bond, and we expected a further increase of the $g_{x}$-value when removing this H-bond. In order to analyze this we replaced the hydrogens of the amino-group in silico with methyl groups, thus removing the intramolecular H-bond. As expected, an upward shift of the $g_{x}$-value is observed (entry 9).

\section{DISCUSSION}

In order to obtain structural insight into a putative $\mathrm{H}$-bond network in the $\mathrm{Y}_{731} \leftrightarrow \mathrm{Y}_{730} \leftrightarrow \mathrm{C}_{439}$ triad of E. coli RNR during radical propagation, 3-aminotyrosine $\left(\mathrm{NH}_{2} \mathrm{Y}\right)$ was site-specifically incorporated at position 730 using the in vivo nonsense suppressor t-RNA/RS methodology. ${ }^{34,33}$ Because the modified 
tyrosine residue has $\mathrm{E}^{\circ \prime}$ of $640 \mathrm{mV}(\mathrm{pH} 7)$, which is $190 \mathrm{mV}^{11}$ less than that of $\mathrm{Y}$ at $\mathrm{pH} 7, \mathrm{NH}_{2} \mathrm{Y}$ serves as a spin trap in radical transport through the $\alpha 2$-subunit. The first spectroscopic evidence for the formation of a $\mathrm{NH}_{2} \mathrm{Y}^{\bullet}$ in $\mathrm{Y}_{730} \mathrm{NH}_{2} \mathrm{Y}-\alpha 2$ was provided by earlier studies using X-band EPR spectroscopy, stopped-flow UV-vis kinetics, ${ }^{11}$ and PELDOR spectroscopy. ${ }^{20}$ We have further characterized the electronic structure of the trapped radical at position 730 by multifrequency EPR spectroscopy and have determined its $g$-values. ${ }^{21}$ The latter analysis suggested strong intermolecular $\mathrm{H}$-bonding interactions around $\mathrm{NH}_{2} \mathrm{Y}^{\bullet}$ that could be essential for the PCET in the $\alpha$-subunit.

The mutant employed here, $\mathrm{Y}_{730} \mathrm{NH}_{2} \mathrm{Y}-\alpha 2$, has activity $5-8 \%$ that of wt- $\alpha 2^{19}$ and provides a means to obtain structural insight in the PCET pathway within the $\alpha 2$-subunit of the $\alpha 2 \beta 2$ complex. Our high-field ENDOR spectra illustrate couplings to several exchangeable protons in a distance range of $<5 \AA$ to the oxygen of $\mathrm{NH}_{2} \mathrm{Y}^{\bullet}$. Several spectral features, but particularly strong resonances at $\pm 0.6 \mathrm{MHz}$ and a weakly coupled deuteron(s) with $2 \mathrm{~A}_{\perp}=-\mathrm{A}_{\|} \approx 0.4 \mathrm{MHz}$, provide fingerprints of the H-bonding interactions of this intermediate. The DFT calculation on the basis of the $\mathrm{X}$-ray structure in the resting state predicts an optimized structure of the $\mathrm{NH}_{2} \mathrm{Y}_{730^{\circ}}$, in which three external deuterons should be visible in the ENDOR spectrum (i.e., with $\mathbf{A}_{x, y, z} \geq 0.1 \mathrm{MHz}$ ), i.e., both exchangeable hydrogens of $\mathrm{Y}_{731}$ and $\mathrm{C}_{439}$ and one deuteron of a water molecule located between $\mathrm{NH}_{2} \mathrm{Y}_{730}$ and $\mathrm{Y}_{413}$ that is conserved in the wt structure. Spectral simulations illustrated that the hyperfine and quadrupole tensors predicted by DFT for this model are in agreement with the experimental spectra within $20 \%$ uncertainty. A more detailed DFT analysis of the $g$-values revealed that the observed unusual $g$-shifts are mostly due to the combined effect of the H-bonds to $\mathrm{Cys}_{439}$ and $\mathrm{Tyr}_{731}$, both nearly perpendicular to the ring plane of $\mathrm{NH}_{2} \mathrm{Y}_{730}$. This is the first combined experimental and theoretical evidence for a $\mathrm{H}$ bond network between the essential residues in the $\alpha 2$ subunit of $E$. coli RNR in an active complex.

The H-bonds and hyperfine couplings observed in this study are assigned to residues that are conserved in the wt structure. Because of the strong similarities in the $\mathrm{X}$-ray structures of wt and $\mathrm{NH}_{2} \mathrm{Y}-\alpha 2$ mutant around residue 730 (Figure S8), our results strongly suggest that the observed $\mathrm{H}$-bond network is conserved also in the 'active' wt enzyme. The work establishes that the $\mathrm{X}$-ray structure of the wt- $\alpha 2$ subunit alone with the unusual configuration of $\mathrm{Y}_{731}$ and $\mathrm{Y}_{730}$ is present in the active $\alpha 2 \beta 2$ complex in solution. We also note that the DFT optimized structure of the intermediate state (Figure 4) reveals distances between the pathway residues $\mathrm{Cys}_{439}-\mathrm{NH}_{2} \mathrm{Y}_{730}-\mathrm{Y}_{731}$ that are considerably shorter than in the $\mathrm{X}$-ray structure of the resting state (Figure 1). Specifically, the $\mathrm{O} \cdots \mathrm{O}$ distance between $\mathrm{NH}_{2} \mathrm{Y}_{730}$ and $\mathrm{Y}_{731}$ decreases from 3.3 (Figure 1) to $2.7 \AA$ (Figure 4) and the $\mathrm{O} \cdots \mathrm{S}$ distance between $\mathrm{NH}_{2} \mathrm{Y}_{730}$ and $\mathrm{Cys}_{439}$ from 3.7 to $3.4 \AA$. The obtained structural data can now be employed to rationalize the proposed mechanism of PCET within $\alpha 2$.

For this goal, the energetics for the radical transfer between $\mathrm{Y}_{731} \leftrightarrows \mathrm{Y}_{730} \leftrightarrows \mathrm{C}_{439}$ were computed as a function of suitably chosen reaction coordinates. Relaxed surface scans were carried out by pulling the $\mathrm{H}$-atom from $\mathrm{Y}_{731} / \mathrm{C}_{439}$ toward $\mathrm{Y}_{730}$ 'via reducing the $\mathrm{O}\left(\mathrm{Y}_{730^{\circ}}\right)-\mathrm{H}$ bond length. For this purpose, an even larger model than 4 (Figure 4) was constructed in order to include the residues around $\mathrm{Cys}_{439}$ and the sugar of the substrate GDP (PDB code $4 \mathrm{R} 1 \mathrm{R},{ }^{31}$ model 7 with WAT1 and model 8 without WAT1, in Figure S6b); a total of 209 and 212 atoms, respectively, were considered in the quantum calculations. We display in Figure 5 the energetics of the radical

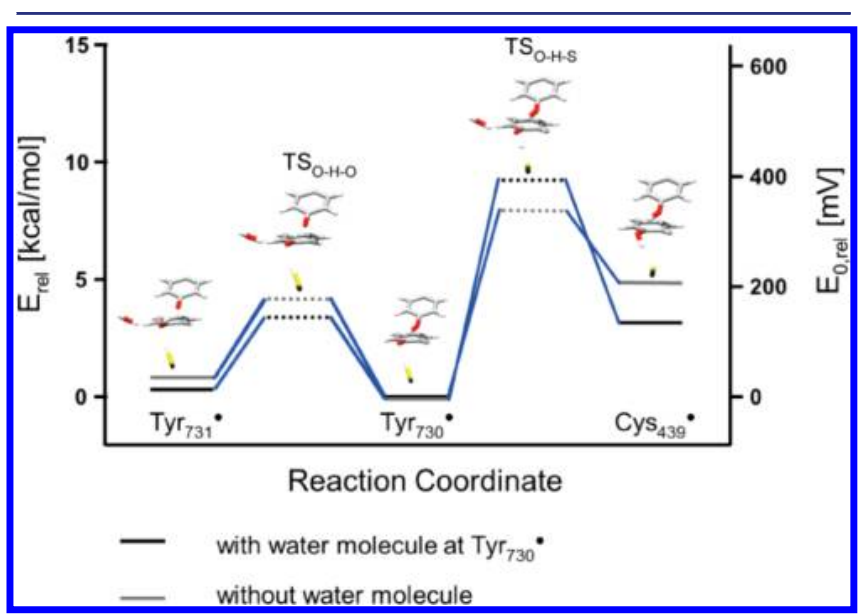

Figure 5. Energy level diagram including the transition states for the PCET pathway residues $\mathrm{Y}_{731}-\mathrm{Y}_{730}-\mathrm{C}_{439}$. The reaction coordinate was investigated using the large models 7 and 8 (Table 2), with and without the water molecule. Shown are only parts of the optimized structures of model 7 (with water molecule).

transfer using models $\mathbf{7}$ and $\mathbf{8}$ and consider explicitly the effect of the water molecule observed in this study. In the calculation with the water molecule, both $\mathrm{Y}_{731}{ }^{\bullet}$ and $\mathrm{Y}_{730}{ }^{\bullet}$ are isoenergetic, whereas radical transfer to $\mathrm{Cys}_{439}$ is endergonic by $\sim 3-4 \mathrm{kcal} /$ mol. From these data it can be estimated that the oxidation potential of $\mathrm{Cys}_{439}$ is about $120 \mathrm{mV}$ greater than that of the tyrosines in the protein environment. Very recent studies on the distribution of the $\mathrm{Y}^{\bullet}$ between residues 356 in $\beta 2$ and 731 and 730 in $\alpha 2$ suggested within error that Y731 and Y730 are isoenergetic. $^{36}$ These results are consistent with the similarities of the reduction potentials of $\mathrm{Y}_{731}{ }^{\bullet}$ and $\mathrm{Y}_{730}{ }^{\bullet}$ obtained in this work. Until now no experimental data are available on the redox gradient toward $\mathrm{C}_{439}$. Kinetic studies of tyrosyl radical reduction by the tripeptide glutathione indicate that the redox potential of the glutathione thiyl radical and the tyrosyl radical is nearly the same at $\mathrm{pH} 7 .{ }^{37}$ However this model system might be too simple to be compared with the $\mathrm{Y}_{730}{ }^{\bullet}$ and $\mathrm{C}_{439}{ }^{\bullet}$ in the active RNR complex.

Upon removal of the water molecule, a destabilization of $\mathrm{Y}_{731}{ }^{\bullet}$ and $\mathrm{Cys}_{439}{ }^{\bullet}$ is observed in the calculation. The activation barrier is diminished for the PCET from $\mathrm{Y}_{730}{ }^{\bullet}$ to $\mathrm{Cys}_{439}{ }^{\bullet}$ by 1.2 $\mathrm{kcal} / \mathrm{mol}$ (from 9.2 to $8.0 \mathrm{kcal} / \mathrm{mol}$ ), whereas the barrier for the PCET from $\mathrm{Y}_{731}{ }^{\bullet}$ to $\mathrm{Y}_{730}{ }^{\bullet}$ is only slightly increased (from 3.1 to $3.4 \mathrm{kcal} / \mathrm{mol}$ ). We point out that the absolute errors for energy barriers are certainly not less than $\sim 2 \mathrm{kcal} / \mathrm{mol}$ in these DFT calculations. However, when comparing trends in very similar systems, as done here, the errors should be much smaller, and an energy shift of $1.2 \mathrm{kcal} / \mathrm{mol}$ between two closely related structures is considered significant. By removing the water molecule, the kinetics of the radical transfer from $\mathrm{Y}_{731}{ }^{\bullet}$ to $\mathrm{Cys}_{439}{ }^{\circ}$ is accelerated by about 1 order of magnitude. The difference is small as compared to the much higher energy barrier dominating the overall kinetic behavior in RNR (the turnover number of $2-10 \mathrm{~s}^{-1}$ corresponds to a ratedetermining step with a barrier of $15-16 \mathrm{kcal} / \mathrm{mol}$ ). Nevertheless, changing a rate constant in a chemical mechanism perturbs the balance between different possible reaction 
channels and could allow off-pathway reactions to compete. We should mention that in the previous work of Siegbahn et al. the transfer from $\mathrm{Y}_{731}$ ' to $\mathrm{Cys}_{439}{ }^{\bullet}$ was studied, but with much smaller model systems and without WAT $1 .{ }^{14}$ Their calculated barrier for the transfer from $\mathrm{Y}_{730}{ }^{\bullet}$ to $\mathrm{Cys}_{439}{ }^{\bullet}$ is almost identical $(8.1 \mathrm{kcal} / \mathrm{mol})$, whereas the barrier for the PCET from $\mathrm{Y}_{731}{ }^{\bullet}$ to $\mathrm{Y}_{730^{\circ}}$ is $1.5 \mathrm{kcal} / \mathrm{mol}$ higher than the one predicted by our calculations $(4.9$ versus $3.4 \mathrm{kcal} / \mathrm{mol})$. In their early calculations, the dispersion interaction was not taken into account and affects the interaction between both tyrosine residues (e.g., the tyrosine-tyrosine distance in the transition state for the radical transfer from $\mathrm{Y}_{731}{ }^{\bullet}$ to $\mathrm{Y}_{730^{\circ}}$, measured by the $\mathrm{C}(-\mathrm{OH})-\mathrm{C}(-\mathrm{OH})$ distance, is $3.25 \AA$ in their calculations and $2.97 \AA$ in ours). We further note that the determination of transition states in quantum chemical calculations makes no $a$ priori assumption about the actual mechanism (e.g., H-atom transfer or PCET of any kind). The calculations simply provide a transition-state structure and associated energy which have the mathematically and physically well-defined property of representing a point on the potential energy surface that is a local maximum in exactly one degree of freedom. The important question of how the electronic structure of the system is to be interpreted at this point is an entirely different subject. In the present case we find the perhaps surprising result that the calculated transition state does not reflect classical $\mathrm{H}$ atom transfer (HAT). If it would be HAT, the calculation would have to show positive spin population on both tyrosine residues and negative spin at the transferring hydrogen; rather one observes essentially no spin on the transferring hydrogen (see Figure S9) and half of the spin density each on both tyrosine $\pi$-electron systems (see Figure S9). ${ }^{38}$ This means that the reaction is best described as a PCET in which the proton and electron move separately. It is noted that our results are in agreement with a recent study by Kaila and Hummer, who used dispersion-corrected DFT for the calculation of the radical transfer between two stacked tyrosine residues. ${ }^{17}$ Their results, like ours for RNR, are in agreement with a colinear PCET mechanism. Similar observations hold for the $Y_{730} \leftrightarrow C_{439}$ radical transfer (see Figure S9b). A more detailed theoretical analysis would involve going significantly beyond the BornOppenheimer approximation and is outside the scope of the present study.

\section{CONCLUSION}

We have presented using a combination of ENDOR spectroscopy and density functional calculations evidence for the structure of the H-bond network around $\mathrm{NH}_{2} \mathrm{Y}_{730}{ }^{\bullet}$ in an $\mathrm{NH}_{2} \mathrm{Y}_{730^{-}} \alpha 2 \beta 2$ complex of $E$. coli RNR competent in nucleotide reduction. The short distances and $\mathrm{H}$-bonding interactions revealed along the radical transfer pathway $\mathrm{Y}_{731} \leftrightarrows \mathrm{Y}_{730} \leftrightarrows \mathrm{C}_{439}$ support the current model of a colinear PCET in the active $\alpha 2$. Our results also suggest the involvement of a water molecule near $\mathrm{Y}_{730}$ in the active complex, which is conserved in available $\mathrm{X}$-ray structures of the wt $\alpha 2$-subunit. The results give insight into the complexity of H-bond interactions, which could regulate the energetics of PCET at the molecular level.

\section{METHODS}

Preparation of High-Field EPR Samples. $\mathrm{Y}_{730} \mathrm{NH}_{2} \mathrm{Y}-\alpha 2$ was prepared as previously described. ${ }^{11}$ Prereduced $\mathrm{Y}_{730} \mathrm{NH}_{2} \mathrm{Y}-\alpha 2$ and $\beta 2$ were combined in an equimolar ratio and concentrated at $4{ }^{\circ} \mathrm{C}$ in a Minicon concentration device (YM-30 membrane) to a final complex concentration of $100 \mu \mathrm{M}\left[\varepsilon_{280} \mathrm{~nm}(\alpha 2+\beta 2) \cong 320 \mathrm{mM}^{-1} \mathrm{~cm}^{-1}\right]$ in
$\mathrm{D}_{2} \mathrm{O}$ buffer consisting $50 \mathrm{mM}$ Hepes, $15 \mathrm{mM} \mathrm{MgSO}_{4}$, and $1 \mathrm{mM}$ EDTA (assay buffer) at $\mathrm{pD}$ 8.0. The concentrated samples were divided into $100 \mu \mathrm{L}$ aliquots, placed in $1.5 \mathrm{~mL}$ Eppendorf tubes, and flash-frozen in liquid $\mathrm{N}_{2}$. High-field EPR samples were prepared by thawing each aliquot on ice and adding CDP and ATP to final concentrations of 2 and $6 \mathrm{mM}$ in a $20 \mu \mathrm{L}$ sample volume. Each reaction was allowed to proceed for $\sim 30 \mathrm{~s}$ at room temperature and was then quenched in an EPR tube by hand freezing with liquid $\mathrm{N}_{2}$. The reaction in $\mathrm{D}_{2} \mathrm{O}$ was carried out after exchanging the $\mathrm{H}_{2} \mathrm{O}$ buffer of prereduced $\alpha 2-\mathrm{NH}_{2} \mathrm{Y}_{730}$ and $\beta 2$ into deuterated assay buffer by 5 concentration/dilution cycles at $4{ }^{\circ} \mathrm{C}$ using a Minicon concentration device and a YM-30 membrane until the solution consisted of $>99 \%$ deuterated buffer. Nucleotide stock solutions were also prepared in deuterated buffer.

High-Frequency Pulsed EPR and ENDOR on $\mathrm{NH}_{2} \mathrm{Y}_{730^{\circ}}$ in $\mathrm{D}_{2} \mathrm{O}$ Buffer. Samples for $94 \mathrm{GHz}$ EPR and ENDOR spectroscopy contained a volume of $\sim 0.25 \mu \mathrm{L}$ in a Suprasil quartz tube from Wilmad (OD $0.5 \mathrm{~mm}$ ) and $0.5 \mu \mathrm{L}$ in a quartz tube from Bruker (OD $0.9 \mathrm{~mm}$ ), respectively. Echo-detected EPR spectra at $94 \mathrm{GHz}$ were recorded at $70 \mathrm{~K}$ on a Bruker E680 W-band with $400 \mathrm{~mW}$ output power. At $70 \mathrm{~K}$ only the $\mathrm{ND}_{2} \mathrm{Y}_{730^{\circ}}$ contributes to the pulsed EPR spectra due to the fast relaxation of the $\mathrm{Y}_{122}{ }^{\bullet}$ in the vicinity of the diiron cluster. ${ }^{39}$ In order to get a spectrum with high signal-to-noise ratio, the shot per points, number of field sweeps, and repetition times had to be adjusted appropriately at $70 \mathrm{~K}$. Experimental conditions are given in the caption of Figure 2. $94 \mathrm{GHz}{ }^{2} \mathrm{H}$ ENDOR measurements were carried out with the Mims ENDOR sequence $(\pi / 2-\tau-\pi / 2-$ $\mathrm{RF}-\pi / 2-\tau-\mathrm{echo})$ at $10 \mathrm{~K}$ and random radio frequency acquisition. $\mathrm{RF}$ pulses were produced with a $250 \mathrm{~W}$ RF amplifier from Amplifier Research (AR). $\tau$ and $\pi / 2$ values were optimized for each experiment and spectral range as described in the figure captions. As the EPR/ ENDOR spectra at $10 \mathrm{~K}$ also contain about $50-60 \%$ contribution of $\mathrm{Y}_{122}{ }^{\bullet}$, the matrix peak of $\mathrm{Y}_{122}{ }^{\bullet}$ was recorded in a separate experiment and subtracted for each spectrum of Figure 3C. However, no H-bonds are observed in $\mathrm{Y}_{122}$, as known from previous studies. ${ }^{22,29,40}$ All displayed ENDOR spectra were normalized for comparison with simulations.

Simulations of ENDOR Spectra. 94-GHz deuterium ENDOR spectra were simulated by using a MATLAB routine developed inhouse that is based on a first order Hamiltonian (high-field condition) for the hyperfine and quadrupolar interaction. ${ }^{23,29}$ Previous simulations of the EPR spectra at two different frequencies ( 9 and $94 \mathrm{GHz})^{21}$ provided a set of hyperfine tensor principal values $\left(\mathbf{A}_{x}, \mathbf{A}_{y}\right.$, $\mathbf{A}_{z}$ ) and Euler angles $(\alpha, \beta, \gamma)$ for the strongly coupled nuclei of $\mathrm{NH}_{2} \mathrm{Y}_{730^{\circ}}$ in $\mathrm{D}_{2} \mathrm{O}$ and $\mathrm{H}_{2} \mathrm{O}$ buffer, i.e., the $\beta$-methylene proton, the ${ }^{14} \mathrm{~N}$ of the amino group. The blind spots produced by the Mims ENDOR sequence were included by multiplying the calculated ENDOR powder pattern with an envelope function given by $I_{\mathrm{ENDOR}}$ $=1-\cos (2 \pi A \tau){ }^{41}$ This is valid for the $I=1$ nuclei considered here, as all quadrupole couplings are much smaller than the hyperfine values. ${ }^{30}$ The simulations of spectra $3 \mathrm{~A}$ and $3 \mathrm{~B}$ did not include the weakly coupled deuteron due to the central hole produced in the simulation by the blind spots of the Mims sequence. For the same reason, the simulation of spectra $3 \mathrm{C}$ was performed without convolution with the blind spot function.

Rmsd values for the orientation selected traces within one kind of experiment (Figure $3 b$ or $c$ ) were summed up and subsequently divided by the number of traces. In both cases, the central part of the spectrum was not considered, i.e., the region of \pm 0.37 and $\pm 0.08 \mathrm{MHz}$ in (b) and (c), respectively. Fitting procedures were not used due to the too large number of parameters involved.

Computational Methodology. Cluster Models 1-8. The cluster models were generated from the crystal structure of the $\mathrm{Y}_{730} \mathrm{NH}_{2} \mathrm{Y}-\alpha 2$ mutant of E.coli RNR from ${ }^{19}$ (PDB code 2XO4). Models 1-6 incorporated, besides the residues $\mathrm{NH}_{2} \mathrm{Y}_{730^{\circ}}, \mathrm{Y}_{731}$, and $\mathrm{C}_{439}$ that are directly involved in the PCET process, the surrounding residues $\mathrm{D}_{334}$, $\mathrm{R}_{411}, \mathrm{Y}_{413}, \mathrm{~S}_{694}, \mathrm{~A}_{695}$, and $\mathrm{N}_{696}$ (see Figure S6). Models 4 and 5 additionally incorporated the water molecule (WAT1 in Figure S6), which is present between $\mathrm{NH}_{2} \mathrm{Y}_{730}{ }^{\circ}$ and $\mathrm{D}_{334}$ in all three molecules of the asymmetric unit of the crystal structure. Models 1-3 contain, in 
addition to WAT1, a second water molecule that is present in only two out of the three molecules in the asymmetric unit of the crystal structure (WAT2 in Figure S6). It is located between $\mathrm{NH}_{2} \mathrm{Y}_{730}{ }^{\circ}$ and $\mathrm{S}_{694}$.

For the calculation of the PCET barriers for the triad $\mathrm{Y}_{731} \leftrightarrow \mathrm{Y}_{730} \leftrightarrow$ $\mathrm{C}_{439}$ more extended models were used in which the residues surrounding $\mathrm{C}_{439}$ and the ribose of GDP are also included. The cluster models were generated from the crystal structure of E.coli RNR with bound substrate (PDB code 4R1R). ${ }^{31}$ The position of the backbone atoms of $4 \mathrm{R} 1 \mathrm{R}$ and $2 \mathrm{XO} 4$ shows practically no deviation in the region of interest (see Figure S8). Besides the region already incorporated in models $\mathbf{5}$ and $\mathbf{6}$, the residues $\mathrm{T}_{303}, \mathrm{~L}_{438}, \mathrm{E}_{441}, \mathrm{C}_{225}, \mathrm{C}_{462}$, and ribose as a mimic for the substrate GDP were taken into account for the extended cluster models. Model 7 (see Figure S6b) includes WAT1 in the same position as in model 4; in model 8 this water molecule is not included (similar to model 6). Because the interactions studied here are very local in nature, we believe that the size of the cluster chosen here should be large enough to cover effects from the protein electrostatics.

For all model structures the side chains of the residues were always fully incorporated. Bonds were truncated in the backbone region between $\mathrm{C}_{\alpha}$ and $\mathrm{C}(\mathrm{C}=\mathrm{O})$ and between $\mathrm{C}_{\alpha}$ and $\mathrm{N}(\mathrm{N}-\mathrm{H})$, respectively, and replaced by a $\mathrm{C}-\mathrm{H}$ bond. If the neighboring residue is present in the model structure (as for $\mathrm{S}_{694}-\mathrm{N}_{696}$ and $\mathrm{NH}_{2} \mathrm{Y}_{730^{\circ}}-$ $\mathrm{Y}_{731}$ ), the respective backbone bonds were not cut. In order to mimic the steric influence of the protein in the native enzyme structure, Cartesian constraints were included in the geometry optimization of the model structures. For all residues the coordinates of the $\mathrm{C}_{\alpha}$ and $\mathrm{C}_{\beta}$ atoms were kept fixed. In case of the truncated GDP model, the bonds between $\mathrm{C} 4$ and $\mathrm{C} 5$ of the ribose as well as the bond between $\mathrm{C} 1$ of the ribose and the base were replaced by a $\mathrm{C}-\mathrm{H}$ bond. In order to preserve the orientation of ribose in the vicinity of $\mathrm{C}_{439}$, Cartesian constraints were imposed on these $\mathrm{C}-\mathrm{H}$ bonds.

For the simulation of the radical transfer relaxed surface scans were carried out by pulling the $\mathrm{H}$-atom from $\mathrm{Y}_{731} / \mathrm{C}_{439}$ toward $\mathrm{Y}_{730}$. Transition-state optimizations were performed using the P-RFO algorithm with an approximate Hessian matrix as an initial Hessian as implemented in ORCA. ${ }^{42,43}$

Small Cluster Model. Small model systems were constructed in order to analyze the influence of $\mathrm{Y}_{731}$ and $\mathrm{C}_{439}$ on the $g$-values of $\mathrm{NH}_{2} \mathrm{Y}_{730^{\circ}}$. For this purpose, large parts of model 4 were removed. The simplest model contains only the 2-amino-4-methyl-phenol radical (2AMPR) representing $\mathrm{NH}_{2} \mathrm{Y}_{730}{ }^{\bullet}$ (Table 2, entry 8). $\mathrm{Y}_{731}$ and $\mathrm{C}_{439}$ are mimicked by the bound neighboring tyrosine (including the peptide bond) and cysteine, respectively. This gives rise to three additional models which are labeled as followed: $\mathrm{NH}_{2} \mathrm{Y}_{730^{\circ}}-\mathrm{C}_{439}, \mathrm{NH}_{2} \mathrm{Y}_{730^{\circ}-}-$ $\mathrm{Y}_{731}, \mathrm{NH}_{2} \mathrm{Y}_{730^{\circ}}-\mathrm{Y}_{731}-\mathrm{C}_{439}$ (Table 2, entries 5-7). Model $\mathrm{NH}_{2} \mathrm{Y}_{730^{\circ}}-$ $\mathrm{Y}_{731}-\mathrm{C}_{439}-$ WAT1 (Table 2, entry 4) contains an additional water molecule (in comparison to Table 2, entry 5). The effect of the intramolecular $\mathrm{H}$-bond in $\mathrm{NH}_{2} \mathrm{Y}_{730^{\circ}}$ was also investigated in one small cluster model (Table 2, entry 9). In this model the intramolecular $\mathrm{H}$ bond is disrupted by substituting the $\mathrm{H}$-atoms of the amino group with methyl groups. In order to mimic the effect of the protein on the geometry, the $\mathrm{C}_{\alpha}$ and $\mathrm{C}_{\beta}$ atom coordinates $\left(\mathrm{C}_{\beta}\right.$ and $\mathrm{C}_{\gamma}$ for 2-AMPR without backbone) were kept fixed during the geometry optimization.

QM Methodology. The optimizations were performed with spin unrestricted RI-BP using the def2-TZVP basis set in conjunction with the def2-TZVP/J auxiliary basis set. ${ }^{44-48}$ Single-point energy calculations were carried out with RIJCOSX ${ }^{24}-\mathrm{B}_{3} \mathrm{LYP}^{48-51}$ using the def2-TZVPP basis set in conjunction with the def2-TZVPP/J as an auxiliary basis set for all atoms. The long-range electrostatic effects of the protein environment were crudely modeled using a dielectric continuum approach on the basis of the conductor-like screening model $(\text { COSMO })^{52}$ with a dielectric constant $(\varepsilon)$ of $4.0 .^{53}$ The EPR calculations were carried out using RIJCOSX-B3LYP using the EPR-II basis set (IGLO-II for sulfur) in accordance with def2-TZVPP/JK as auxiliary basis set for all atoms. ${ }^{54-56}$ Grimme's 2006 semiempirical dispersion correction (keyword VDW06 in ORCA) was included to account for dispersion effects. ${ }^{57}$ Numerical frequency calculations were carried out at the same level of theory as for the optimization. From these frequency calculations the zero point energies for the relative energies were derived.

\section{ASSOCIATED CONTENT}

\section{S Supporting Information}

Energy-minimized DFT models $(\mathbf{1}-\mathbf{3}, \mathbf{5}, \mathbf{6})$ for the $\mathrm{NH}_{2} \mathrm{Y}_{730}$ • intermediate as well as cluster models $\mathbf{1}, 7$, and $\mathbf{8}$. Influence of second sphere resudues on $\mathrm{H}$-bond interactions to $\mathrm{NH}_{2} \mathrm{Y}_{730^{\circ}}$. Comparison of PDB structures 2X0X, 2XO4, and 4R1R. Spin density plots for the radical transfer transition states $\mathrm{Y}_{731} \leftrightarrow$ $\mathrm{Y}_{730}$ and $\mathrm{Y}_{730} \leftrightarrow \mathrm{C}_{439}$. This information is available free of charge via the Internet at http://pubs.acs.org.

\section{AUTHOR INFORMATION}

\section{Corresponding Author}

Marina.Bennati@mpibpc.mpg.de; frank.neese@cec.mpg.de

Notes

The authors declare no competing financial interest.

\section{ACKNOWLEDGMENTS}

T.A. and M.B. would like to thank E.C. Minnihan, M.R. Seyedsayamdost, and T. Nick for their support in this work. The work was funded by the DFG-IRTG 1422, and the Max Planck Society (T.A. and M.B.). C.R. and F.N. gratefully acknowledge financial support by the Collaborative Research Center SFB 624. The financial support to J. S. from NIH GM29595 is gratefully acknowledged.

\section{REFERENCES}

(1) Jordan, A.; Reichard, P. Annu. Rev. Biochem. 1998, 67, 71.

(2) Stubbe, J.; van Der Donk, W. A. Chem. Rev. 1998, 98, 705.

(3) Hofer, A.; Crona, M.; Logan, D. T.; Sjöberg, B.-M. Crit. Rev. Biochem. Mol. Biol. 2012, 47, 50

(4) Nordlund, P.; Sjoberg, B. M.; Eklund, H. Nature 1990, 345, 593.

(5) Uhlin, U.; Eklund, H. Nature 1994, 370, 533.

(6) Bennati, M.; Robblee, J. H.; Mugnaini, V.; Stubbe, J.; Freed, J. H.; Borbat, P. I. Am. Chem. Soc. 2005, 127, 15014.

(7) Climent, I.; Sjoberg, B. M.; Huang, C. Y. Biochemistry 1992, 31, 4801.

(8) Ekberg, M.; Sahlin, M.; Eriksson, M.; Sjoberg, B. M. J. Biol. Chem. 1996, 271, 20655.

(9) Yee, C. S.; Chang, Ge, J.; Nocera, D. G.; Stubbe, J. J. Am. Chem. Soc. 2003, 125, 10506.

(10) Yee, C. S.; Seyedsayamdost, M. R.; Chang, M. C. Y.; Nocera, D. G.; Stubbe, J. Biochemistry 2003, 42, 14541.

(11) Seyedsayamdost, M. R.; Xie, J.; Chan, C. T.; Schultz, P. G.; Stubbe, J. I. Am. Chem. Soc. 2007, 129, 15060.

(12) Holder, P. G.; Pizano, A. A.; Anderson, B. L.; Stubbe, J.; Nocera, D. G. I. Am. Chem. Soc. 2011, 134, 1172.

(13) Stubbe, J.; Nocera, D. G.; Yee, C. S.; Chang, M. C. Chem. Rev. 2003, 103, 2167.

(14) Siegbahn, P. E. M.; Eriksson, L.; Himo, F.; Pavlov, M. J. Phys. Chem. B 1998, 102, 10622.

(15) DiLabio, G. A.; Johnson, E. R. I. Am. Chem. Soc. 2007, 129, 6199.

(16) Reece, S. Y.; Hodgkiss, J. M.; Stubbe, J.; Nocera, D. G. Philos. Trans. R. Soc., B 2006, 361, 1351.

(17) Kaila, V. R. I.; Hummer, G. I. Am. Chem. Soc. 2011, 133, 19040.

(18) Seyedsayamdost, M. R.; Yee, C. S.; Reece, S. Y.; Nocera, D. G.; Stubbe, J. I. Am. Chem. Soc. 2006, 128, 1562.

(19) Minnihan, E. C.; Seyedsayamdost, M. R.; Uhlin, U.; Stubbe, J. J. Am. Chem. Soc. 2011, 133, 9430.

(20) Seyedsayamdost, M. R.; Chan, C. T.; Mugnaini, V.; Stubbe, J.; Bennati, M. I. Am. Chem. Soc. 2007, 129, 15748.

(21) Seyedsayamdost, M. R.; Argirevic, T.; Minnihan, E. C.; Stubbe, J.; Bennati, M. I. Am. Chem. Soc. 2009, 131, 15729. 
(22) Un, S. Magn. Reson. Chem. 2005, 43, S229.

(23) Bennati, M.; Farrar, C. T.; Bryant, J. A.; Inati, S. J.; Weis, V.; Gerfen, G. J.; Riggs-Gelasco, P.; Stubbe, J.; Griffin, R. G. J. Magn. Reson. 1999, 138, 232.

(24) Klein, E. L.; Astashkin, A. V.; Ganyushin, D.; Riplinger, C.; Johnson-Winters, K.; Neese, F.; Enemark, J. H. Inorg. Chem. 2009, 48, 4743.

(25) Radoul, M.; Bykov, D.; Rinaldo, S.; Cutruzzolà, F.; Neese, F.; Goldfarb, D. I. Am. Chem. Soc. 2011, 133, 3043.

(26) Radoul, M.; Sundararajan, M.; Potapov, A.; Riplinger, C.; Neese, F.; Goldfarb, D. Phvs. Chem. Chem. Phvs. 2010, 12, 7276.

(27) Sundararajan, M.; Riplinger, C.; Orio, M.; Wennmohs, F.; Neese, F. In Encyclopedia of Inorganic Chemistry; John Wiley \& Sons, Ltd: Hoboken, NJ, 2009.

(28) Dam, P. J. v.; Willems, J.; Schmidt, P. P.; Pötsch, S.; Barra, A.; Hagen, W. R.; Hoffman, B.; Anderson, K. K.; Gräslund, A. J. Am. Chem. Soc. 1998, 120, 5080.

(29) Bar, G.; Bennati, M.; Nguyen, H. H.; Ge, J.; Stubbe, J. A.; Griffin, R. G. I. Am. Chem. Soc. 2001, 123, 3569.

(30) Doan, P. E.; Lees, N. S.; Shanmugam, M.; Hoffman, B. Appl. Magn. Reson. 2010, 37, 763.

(31) Eriksson, M.; Uhlin, U.; Ramaswamy, S.; Ekberg, M.; Regnström, K.; Sjöberg, B.-M.; Eklund, H. Structure 1997, 5, 1077.

(32) Yokoyama, K.; Uhlin, U.; Stubbe, J. L.Am. Chem. Soc. 2010, 132, 8385.

(33) Sinnecker, S.; Flores, M.; Lubitz, W. Phys. Chem. Chem. Phys. 2006, 8, 5659.

(34) Alfonta, L.; Zhang, Z.; Uryu, S.; Loo, J. A.; Schultz, P. G. J. Am. Chem. Soc. 2003, 125, 146662.

(35) Liu, C. C.; Schultz, P. G. Annu. Rev. Biochem. 2010, 79, 413.

(36) Yokoyama, K.; Smith, A. A.; Corzilius, B.; Griffin, R. G.; Stubbe, I. I. Am. Chem. Soc. 2011, 133, 18420.

(37) Folkes, L. K.; Trujillo, M.; Bartesaghi, S.; Radi, R.; Wardman, P. Arch. Biochem. Biophvs. 2011, 506, 242.

(38) Mayer, M.; Hrovat, D. A.; Thomas, J. L.; Borden, W. T. J. Am. Chem. Soc. 2002, 124, 11142.

(39) Lawrence, C. C.; Bennati, M.; Obias, H. V.; Bar, G.; Griffin, R. G.; Stubbe, J. Proc. Natl. Acad. Sci. U.S.A. 1999, 96, 8979.

(40) Bender, C. J.; Sahlin, M.; Babcock, G. T.; Barry, B. A.; Chandrashekar, T. K.; Salowe, S. P.; Stubbe, J.; Lindstrom, B.; Petersson, L.; Ehrenberg, A.; Sjoberg, B.-M. J. Am. Chem. Soc. 1989, 111, 8076.

(41) Schweiger, A.; Jeschke, G. Principles of Pulsed Electron Paramagnetic Resonance; Oxford University Press: Oxford, U.K., 2001.

(42) Backer, J. I. Comput. Chem. 1986, 7, 385.

(43) Neese, F., Ph.D., University of Bonn, Bonn, Germany, 2007.

(44) Weigend, F.; Ahlrichs, R. Phvs. Chem. Chem. Phvs. 2005, 7, 3297.

(45) Schäfer, A.; Huber, C.; Ahlrichs, R. J. Chem. Phys. 1994, 100, 5829.

(46) Perdew, J. P. Phys. Rev. B 1986, 33, 8822.

(47) Perdew, J. P. Phys. Rev. B 1986, 34, 7406.

(48) Becke, A. D. Phvs. Rev. A 1988, 38, 3098.

(49) Lee, C.; Yang, W.; Parr, R. G. Phvs. Rev. B 1988, 37, 785.

(50) Becke, A. D. I. Chem. Phvs. 1993, 98, 5648.

(51) Neese, F.; Wennmohs, F.; Hansen, A.; Becker, U. Chem. Phys. 2009, 356, 98.

(52) Klamt, A.; Schürmann, G. I. Chem. Soc. Perk. T 1993, 2, 799.

(53) Siegbahn, P. E. M.; Blomberg, M. R. A.; Pavlov, M. Chem. Phys. Lett. 1998, 292, 421.

(54) Barone, V. Recent advances in density functional methods; World Scientific Publishing, Co.: London, 1996; Vol. 1, Part I.

(55) Kutzelnigg, W.; Fleischer, U.; Schindler, M. NMR Basic Principles and Progress; Springer-Verlag: Berlin, Germany, 1990; Vol. 23.

(56) Weigend, F. Phvs. Chem. Chem. Phvs. 2002, 4, 4285.

(57) Grimme, S. I.Comput. Chem. 2006, 27, 1787.

\section{NOTE ADDED AFTER ASAP PUBLICATION}

The toc/abstract, Figure 2, and Table 2 graphics contained errors in the version published ASAP October 16, 2012; the correct version reposted October 24, 2012. 